\title{
LOS DILEMAS DE LA LAICIDAD POSITIVA: UN ANÁLISIS A PARTIR DEL CASO PERUANO*
}

\author{
Betzabé Marciani Burgos \\ Pontifica Universidad Católica del Perú
}

RESUMEN. El retorno del fenómeno religioso, que se produce en el contexto de la denominada crisis de la modernidad, ha puesto en entredicho los alcances del proceso de secularización de las sociedades occidentales. Hoy se discute el papel que debería cumplir la religión en el ámbito público y su incidencia en el modelo de laicidad de los Estados constitucionales. De este modo, los conceptos de laicidad y de neutralidad estatal, propios de la tradición liberal, son cuestionados por algunos autores y se proponen modelos alternativos de relación entre Estado e Iglesia (o Iglesias), sobre la base de una concepción positiva de la libertad religiosa y de una valoración de lo religioso (y de ciertas religiones) por su trascendencia cultural o social. El propósito de este trabajo es cuestionar los alcances de la llamada laicidad positiva y sus efectos en la protección de los derechos de libertad e igualdad, con especial referencia al caso peruano. sitiva.

Palabras clave: Secularización, laicidad, neutralidad, libertad religiosa, libertad po-

\section{The Positive Laicism Dilemmas: an Analysis of the Peruvian Case}

ABSTRACT. The return of the religious phenomenon, made in the so-called modernity crisis context, has brought into question the significance of the occidental societies' secularization procedure. Nowadays, we discuss the role that the religion should fulfill in the public sphere and its influence in the constitutional states' laicism model. In this way, the state's laicism and neutrality, concepts of liberal tradition, are questioned by some authors and alternative models of the relationship between State and Church (or Churches) are being proposed. This made on the basis of a positive conception of the religious liberty and an assessment of the religious (and some religions) by their cultural or social significance. The purpose of this work is to question the significance of the socalled positive laicism and its effects in the protection of the liberty and equality rights, with special reference to the Peruvian case.

Keywords: Secularization, laicism, neutrality, freedom of religion, positive liberty.

\footnotetext{
* Fecha de recepción: 15 de abril de 2015. Fecha de aceptación: 4 de junio de 2015.

Este trabajo es parte del proyecto de investigación denominado Cuestionamientos a la aplicación del principio de laicidad en el Estado peruano, ganador del Concurso Anual de Investigación 2013, y que ha sido financiado por la Dirección de Gestión de la Investigación (DGI) de la Pontificia Universidad Católica del Perú.
} 


\section{INTRODUCCIÓN}

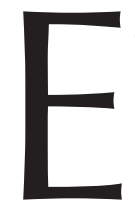

1 propósito de este trabajo es cuestionar el modelo de laicidad positiva que, según sus defensores, habría sido adoptado por el texto constitucional peruano, modelo que se ubicaría en un punto medio entre el laicismo (agresivo frente a la religión) y el compromiso de tipo confesional.

La defensa del modelo de laicidad positiva se da en el contexto de la apertura al discurso religioso en el ámbito público y coincide con el llamado retorno del fenómeno religioso y el declive del proceso de secularización. Si bien el problema de la laicidad del Estado se ubica en el ámbito de la discusión filosófico política y jurídica, mientras que la discusión en torno a la secularización corresponde al ámbito sociológico, los cambios experimentados en las sociedades post seculares han influido en la discusión en torno a la laicidad de los actuales Estados constitucionales. Por esa razón, este trabajo empezará con una aproximación al debate sobre el retorno del fenómeno religioso en las sociedades democrática de hoy.

El retorno de lo religioso se ha manifestado en una revalorización del discurso religioso en la esfera pública. Además de los problemas que ello puede suscitar en relación con el tipo de razonamiento que debería corresponder a la deliberación de los asuntos públicos en las sociedades democráticas, dicha revalorización tiene incidencia en el modelo de laicidad que se adopte y, particularmente, en la idea de una laicidad positiva supuestamente abierta a la participación de lo religioso en el ámbito público. Este tema será tratado en el segundo apartado de este trabajo.

Las tres últimas secciones del artículo se refieren, de forma más específica, a la cuestión de la laicidad y al caso peruano. Tomando en cuenta los propósitos de este artículo, la discusión acerca de la laicidad del Estado no abarcará los diversos y complejos procesos presentados en otros países de la región y que merecerían un tratamiento aparte. Por su similitud con el caso peruano, sí se hará especial mención al caso español.

\section{EL MITO MODERNO DE LA SECULARIZACIÓN Y EL RETORNO DE LO RELIGIOSO}

Como señala Jürgen HABERMAS, el cambio de época —que va de fines de los años ochenta a inicios de los noventa - ha supuesto una revaloración del significado político de la religión en el mundo entero (HABERMAS, 2006: 121); pero, principalmente, ha significado la puesta en cuestión de uno de los pilares básicos del modelo occidental del Estado democrático de derecho: el concepto de secularización o de laicidad del Estado ${ }^{1}$.

1 Aunque varios de los autores los usan de forma indiferente, MACLURE y TAYLOR sostienen que debe evitarse confundir laicización con secularización: «La laicización es el proceso por el que el Estado afirma su independencia respecto a la religión, mientras que uno de los elementos de la secularización es la erosión de la influencia de la religión en las prácticas sociales y en la forma de vivir la vida personal. Si la laicización es un proceso político que se inscribe en el derecho positivo, la secularización es más bien un fenómeno sociológico que se encarna en los conceptos del mundo y en la forma de vida de las personas» (MACLURE y TAYLOR, 2011: 28). 
El mensaje optimista de la teoría de la modernidad, propio de la década de los cincuenta, apuntaba a que la mayor satisfacción de las demandas de recursos, asociadas a los conflictos de intereses, supondría una reducción de los conflictos de tipo ideológico y de los basados en la identidad. Los efectos de la industrialización, el incremento de los centros urbanos y la secularización reducirían el significado de categorías como las de creer o ser y enfatizarían la del tener. De este modo, los conflictos sociales se reconducirían a la vía de los conflictos económicos (OFFE, 1998: 121-122).

Sin embargo, las promesas de la modernidad no se cumplieron y, como se advierte, hoy existe una proliferación de demandas basadas en la identidad y una presencia cada vez mayor en el ámbito público de elementos vinculados a concepciones comprehensivas y creencias antes restringidas al ámbito privado (un ejemplo de ello es el llamado resurgimiento del tema religioso).

La idea de progreso de la modernidad estaba ligada a una concepción racionalista y cientificista, así como a una concepción secularista que tiene su fuente en el ateísmo ilustrado y desde cuyo punto de vista la experiencia religiosa —entendida como un residuo del pensamiento mágico de nuestras primeras etapas de evolución- poco a poco sería superada por la lógica del conocimiento y el desarrollo ${ }^{2}$. A esta visión responde, por ejemplo, un cierto tipo de intelectual que —en opinión de Peter BERGER (BERGER, 2008) - ha terminado por reproducir un pensamiento tan fundamentalista como el que denunciaba respecto de sus oponentes creyentes. Se trata de un esquema de pensamiento cuya ceguera ha sido incapaz de entender y anticipar los cambios producidos en los últimos años en el mundo en torno al fenómeno religioso ${ }^{3}$.

El retorno de lo religioso puede ser explicado de diversas formas, a partir de lo que el fin de las promesas de la modernidad y el surgimiento de la globalización (principalmente de su modelo económico neoliberal) han significado en cada contexto.

Aunque como advierten Berger, FerRARA e incluso Habermas, en los Estados Unidos no es posible hablar de un retorno de la religión, en la medida que éste ha sido un elemento profundamente enraizado en la cultura norteamericana, para algunos autores, la acentuación de la dimensión público-política que ha adquirido la religión

2 Para Habermas, esta versión de ciudadanos seculares, que aún pervive, considera a las tradiciones religiosas y a la religión como «una reliquia arcaica de las sociedades premodernas» y en esa medida es imposible incluirlos en el tipo de diálogo cooperativo que propone el autor, y que analizaremos luego (HABERMAS, 2006: 146).

Para una sugerente crítica a la agresiva actitud racionalista e ilustrada, defendida por varios autores liberales actuales frente al fenómeno religioso, vid. el agudo ensayo de Terry EAGLETON, Razón, fe y revolución (2012).

3 Según BERGER, por ejemplo, el fenómeno de europeización de la elite cultural norteamericana (acentuadamente secularista) —ocurrida a partir de los años treinta del siglo pasado- puede explicar la perplejidad con que ha sido percibida la acentuación de la manifestación pública de lo religioso en los Estados Unidos en los años recientes. Y es que, sobre la base de una concepción secularista propia de algunos países europeos (principalmente del modelo francés), se pretendió ocultar lo que siempre fue una realidad latente en la sociedad norteamericana, esto es, el hecho de ser una sociedad profundamente religiosa (probablemente, como dice el autor, la sociedad más religiosa del mundo occidental). Lo que se ha producido en los Estados Unidos (pero también en otros países como la India o Turquía), no ha sido un resurgimiento del fenómeno religioso - pues éste nunca se fue-, sino, más bien, una mayor presencia de éste en el espacio público.

De la misma opinión es Alessandro FERRARA, para quien la presencia del fenómeno religioso en las sociedades occidentales ha sido permanente, aunque ocultada por la ceguera de la ideología de la secularización (FERRARA, 2007). 
en años recientes corresponde a la enorme fuerza que ha ido tomando el movimiento evangélico y que puede explicarse como una consecuencia de los tiempos de inseguridad y fragilidad en que vivimos. Para FRASER, por ejemplo, el auge del evangelismo en los Estados Unidos es producto de lo que ella denomina «la sociedad de la inseguridad», que describe la situación actual de la sociedad norteamericana:

Esta sociedad es la heredera de «la sociedad del bienestar», que está asociada a la socialdemocracia del periodo anterior. A diferencia de esta última, la nueva sociedad institucionaliza una mayor inseguridad en las condiciones de vida de muchas personas. Como observé antes, disminuye las prestaciones sociales a la vez que institucionaliza formas más precarias de trabajo asalariado, que incluyen la subcontratación, el trabajo temporal y el trabajo no sindicalizado, con salarios bajos y escasos beneficios. La consecuencia es una mayor inseguridad, a la que da respuesta el cristianismo evangélico (FrASER, 2008: 202).

Los actuales tiempos de incertidumbre y fragilidad — la «modernidad líquida» a la que se refiere Zygmunt BAUMAN (BAUMAN, 2006)_, permitirían explicar el resurgimiento del fenómeno religioso en el contexto de otras sociedades occidentales, beneficiadas por el desarrollo económico, pero signadas también por el sentimiento de ansiedad que parece acompañar a este modelo de desarrollo.

Para Tony JUDT, por ejemplo, el fin del Estado de bienestar en Europa, la adopción de un modelo económico que convierte la sociedad en una sociedad de desempleo y subempleo, y el desprestigio de lo político y los políticos han abierto las puertas a la religión y a otras experiencias que apuntan a colmar nuestras expectativas éticas o de dirección moral. Eso explicaría, por ejemplo, la gran aceptación popular que han tenido ciertas personalidades religiosas (como el papa Juan Pablo II, principalmente entre los jóvenes), quienes han sido capaces de proponer un discurso público dirigido a satisfacer esas necesidades (JUDT, 2011: 172).

El análisis que subyace al surgimiento de los movimientos fundamentalistas o extremistas en otros lugares del mundo (principalmente, el caso del fundamentalismo islámico), suma a la ansiedad derivada de los nuevos tiempos las frustraciones de un pasado no resuelto. HABERMAS, por ejemplo, lo asocia a los procesos de colonización y descolonización, y a la implantación del modelo de modernización capitalista en contextos que nunca fueron favorables al mismo, tanto desde el punto de vista social como cultural (HABERMAS, 2006: 122).

En el caso de la incidencia de este tipo de manifestaciones dentro de las sociedades occidentales (especialmente de varios países europeos), TODOROV señala como una de sus causas la situación de exclusión de muchos inmigrantes musulmanes. Como explica el autor, el sentimiento de marginalidad de muchos musulmanes que van a radicar a países europeos, y que proceden de familias campesinas tradicionales, los lleva a refugiarse en su identidad tradicional. En las siguientes generaciones esta situación se agrava: «Los que nacen en Occidente ya no pueden recurrir a esa identidad, por lo que a algunos les tientan los esquemas simplistas que ofrecen los predicadores islamistas, una tradición imaginaria que se convierte en su marco mental» (TODOROV, 2008: 218).

En América Latina, lo religioso ha sido un elemento constante en la vida social y también política. Las iniciativas secularistas no han calado de forma determinante en la vida pública de las naciones (con excepción quizá de algunos países como México) y, más bien, lo que ha persistido es un permanente conflicto entre las Iglesias institu- 
cionalizadas (principalmente la Iglesia católica) — con una fuerte presencia en la vida pública- y las iniciativas de implementación de modelos laicos por parte del Estado (por ejemplo, en los ámbitos de la educación, las instituciones castrenses, los actos protocolares de Estado, etc. $)^{4}$. Actualmente, la presencia significativa de movimientos evangélicos en los países latinoamericanos — que, como en los Estados Unidos, tienen una agenda y un accionar público muy claro_- es también determinante ${ }^{5}$.

La heterogénea realidad mundial que hoy se presenta respecto del fenómeno religioso permite comprobar que — como dice BERGER - la modernidad hoy más que secularismo es pluralismo, y el pluralismo no se caracteriza por la ausencia de Dios sino por «la presencia de muchos dioses» ${ }^{6}$. Por eso, el retorno de lo religioso puede leerse de diversas formas y no significa necesariamente el retorno de una religión institucionalizada o de la Iglesia o las Iglesias.

Ulrich BECK, por ejemplo, se ha referido a la individualización de la religión propia del espíritu cosmopolita de nuestros días. Para el autor, paradójicamente, la secularización propia de la modernidad le ha hecho un gran favor a la religión, pues le ha quitado el peso de tener que justificar su competencia en materia de racionalidad del conocimiento (ese peso le ha sido trasladado a la ciencia o al Estado), y la ha restringido al campo de la espiritualidad y la religiosidad ${ }^{7}$. Esto ha ido unido a un proceso de

4 En este trabajo resulta imposible dar cuenta de la diversidad y complejidad de estos procesos producidos en los países latinoamericanos. Investigaciones como las de BLANCARTE (2011, 2008), BOHOSLAVSKY (2013) o HuACO (2013) son importantes para entender la particularidad de cada proceso.

BOHOSLAVSKY, por ejemplo, se ha referido a algunos de los conflictos presentados, especialmente desde la década de los ochenta y que se han centrado en temas vinculados a la legislación de familia. Así, en 1987 se debatió y se logró aprobar el divorcio en Argentina, con fuerte oposición de la Iglesia. Lo mismo ocurrió el 2004 en Chile, tras un intenso y largo debate que se originó en la década de los noventa. En este mismo Estado, el año 2006 se produjo la discusión sobre la comercialización de la denominada «píldora del día después», con idéntica oposición de la Iglesia católica (BOHOSLAVSKY, 2013: 35).

De igual forma, VAGGIONE alude al modo en que desde el feminismo y el movimiento por la identidad sexual se vienen presentando demandas dirigidas a lograr la efectiva separación entre el Estado y la Iglesia en estos ámbitos. Sin embargo, como dice el autor, la jerarquía católica ha sabido conformar en la región un bloque compuesto por actores políticos y organizaciones de la sociedad civil que busca influir en las políticas públicas a través de estrategias como la judicialización y el uso de argumentaciones científicas y bioéticas (VAGGIONE, 2008: 25).

En el Perú, actualmente somos testigos de la activa movilización de la Iglesia católica y de las Iglesias evangélicas contra cualquier tipo de iniciativa legislativa que pretenda garantizar los derechos familiares de los homosexuales y contra la posibilidad de que la mujer pueda interrumpir un embarazo en determinados supuestos.

5 En relación a la presencia de movimientos evangélicos es evidente su crecimiento en la región. Así pues, «mientras que todavía hasta 1950 el porcentaje de no católicos es mínimo (entre un 2 y un 5 por 100), a principios del siglo XXI esa cifra se sitúa entre el 15 y el 20 por 100 de la población latinoamericana, aproximadamente. Hay países como Brasil que tienen ya más de un 30 por 100 de no católicos» (BLANCARTE, 2008: 161).

Como refiere BoHOSLAVSKY, la identidad protestante en Latinoamérica puede agruparse en dos sectores bien diferenciados. Por un lado, el sector protestante clásico, abierto al diálogo interreligioso con la Iglesia católica y dispuesto a adaptarse a las exigencias del Estado democrático liberal y su defensa de los derechos humanos y, por el otro lado, el sector fundamentalista vinculado a los movimientos pentecostales, pero cercano también a la línea de pensamiento más conservadora de la Iglesia católica (BOHOSLAVSKY, 2013: 36-37).

6 El autor señala dos excepciones a esta realidad dominante: el supuesto de algunos países de Europa occidental y central (el supuesto del Eurosecularity) y la existencia de una élite cultural internacional (yo diría cosmopolita) o lo que el autor llama la globalización de la inteligencia ilustrada europea (BERGER, 2008).

7 Esta afirmación puede ser discutible, pues, en ocasiones, parte del discurso religioso se traslapa con discursos referidos a una moral que tiene la pretensión de ser verdadera. En la esfera púbica, el discurso religioso 
desacoplamiento de la religión (o desinstitucionalización) y de reavivamiento de la fe subjetiva, con un discurso centrado en la búsqueda de la perfección individual (BECK, 2009: 31-38).

Aunque, como dice el autor, el fenómeno de la secularización (como el de la modernidad) no ha sido lineal, sino distinto en cada contexto, parece ser que el declive de las instituciones religiosas ha supuesto un aumento de la religiosidad individual (BECK, 2009: 48-49). Su tesis central es que actualmente el fenómeno religioso está caracterizado por una individualización de la experiencia religiosa (lo que llama, la existencia de un «Dios personal»), acorde al propio proceso de individualización de la sociedad de la globalización y al auge del modelo económico capitalista.

La desdogmatización y desinstitucionalización de la religión no lleva, sin embargo, a una multiplicación de credos religiosos. Según BECK, lo que se presenta, más bien, es una estandarización de la oferta de los «productos religiosos»-que sigue la lógica del mercado- y que se puede constatar en la proliferación de ofertas de credos minimalistas, simples y sencillos, que pueden resumirse en frases como: «Dios te ama, ¡Jesús te redime!, puedes salvarte», en vez de un énfasis en interpretaciones teológicas y doctrinarias (BECK, 2009: 98-99) ${ }^{8}$.

La abundancia de la oferta y la demanda religiosa en la actualidad [BECK se refiere, por ejemplo, a la gran cantidad de ofertas religiosas que aparecen en internet y que crean un verdadero bazar inabarcable, del cual los individuos toman lo que les gusta (BECK, 2009: 137)] respondería a la necesidad que tienen los individuos de volverse creadores de su propia identidad — «progresivamente destradicionalizada e invivible a causa del proceso de individualización y globalización» (BECK, 2009: 131) — en un mundo dominado por el riesgo y el libre mercado?

no sólo implica afirmaciones sobre lo espiritual y los misterios de la fe, sino también sobre hechos referidos a la naturaleza humana, la sexualidad o la bioética, por ejemplo, respecto de los cuales se supone que existe conocimiento y verdad.

Cuando ciertos líderes religiosos hablan de la homosexualidad como un hecho anormal o la califican como una enfermedad (que incluso afirman — desde ciertas propuestas pseudocientíficas — podría curarse), o cuando al hablar del aborto o de la llamada píldora del día siguiente se refieren al momento del inicio de la vida, no sólo presentan argumentos de tipo religioso (como que Dios nos dio la vida y por eso tiene carácter sagrado e indisponible), sino argumentos supuestamente científicos.

8 La inserción de la oferta religiosa en la lógica del mercado puede llevar, sin embargo, al riesgo de banalización de lo religioso. Como dice BECK: «La desdogmatización pragmática de las religiones es ambivalente, abre las puertas de par en par a la banalización y trivialización: los hoteles wellness se decoran con máximas budistas, el analfabetismo religioso se propaga, los ateos ni siquiera saben en qué Dios ya no creen» (BECK, 2009: 95). En ese mismo sentido van también las agudas críticas de EAGLETON a la espiritualidad new age, a la que califica como una «caricatura de lo espiritual», un refugio o forma de escape frente al «capitalismo brutalmente pragmático» (EAGLETON, 2012: 61).

9 Para BECK, los principios del mercado y de elección individual se han instalado en la religión en América — no sólo en los Estados Unidos, sino en las dos Américas (con la aparición de una gran oferta de productos religiosos duros)_, pero también se expande en Europa (respecto del cristianismo, pero también en las variadas ofertas del Islam y de otras alternativas espirituales de tipo esotéricas o new age). En las culturas postcoloniales (Sudamérica, África y parte de Asia), el fenómeno de la subjetivación de la fe es un poco distinto y se manifiesta a través de nuevos movimientos religiosos que se desprenden de los lazos coloniales para adoptar formas mixtas de «superstición» primitiva y de religiosidad autorizada (BECK, 2009: 149-179). 


\section{LA REVALORIZACIÓN DEL DISCURSO RELIGIOSO EN LA ESFERA PÚBLICA Y SU INCIDENCIA EN EL MODELO DE LAICIDAD}

El retorno de lo religioso ha provocado un cuestionamiento a la tradicional idea secular de confinamiento de lo religioso al ámbito privado, y una cada vez mayor presencia de la religión (de sus manifestaciones — ritos, símbolos, etc.—, pero también de su discurso) en la esfera pública. Frente a esto, autores como John RAWLS o Jürgen HABERMAS se han pronunciado sobre el sentido que tendrían las razones religiosas en el espacio público dentro de un Estado democrático y laico.

En el debate público-político lo que vale son las razones públicas, dice RAWLS ${ }^{10}$. Aunque los participantes lleven consigo sus propias doctrinas religiosas - las cuales pueden ser la base sobre la que se sustenta su convicción sobre ciertos principios de justicia (como la igualdad)_, en el debate que surge ante la aparición de conflictos sobre cuestiones de justicia política (esto es, cuando es menester justificar nuestros juicios políticos) será necesario ofrecer razones públicas para defender nuestra posición (RAWLS, 2002: 53). En términos de RAWLS:

Justificar nuestros juicios políticos ante los demás significa convencerles mediante el uso de la razón pública, es decir, mediante formas de razonamiento e inferencias apropiadas a las cuestiones políticas fundamentales, y apelando a creencias, razones y valores políticos de los que cabe razonablemente esperar que los otros también reconocerán. La justificación pública parte de algún consenso previo, esto es, de premisas que todas las partes en desacuerdo, supuestamente libres e iguales y plenamente capaces de razón, pueden razonablemente compartir y libremente suscribir (RAWLS, 2002: 53).

No obstante, el autor es cauto al referirse al ámbito en el que el uso de razones públicas sería exigible. No lo sería para todas las cuestiones públicas ni políticas, sino únicamente en las discusiones acerca de los «elementos constitucionalmente esenciales» y en relación con las «cuestiones de justicia básica», y señala como ejemplo el caso de las deliberaciones efectuadas por la Corte Suprema norteamericana (RAWLS, 1995: 205 y 207).

De forma más específica, en Una revisión de la idea de razón pública RAWLS establece una distinción entre lo que, por un lado, denomina el «foro político público» - referido al discursos de los jueces y sus decisiones, al de los funcionarios públicos (principalmente del Ejecutivo y el Legislativo), y al discurso de los candidatos a cargos públicos-, donde resulta necesario el uso de la razón pública, y, por otro lado, lo que denomina «cultura de base» (o cultura de la sociedad civil), en la que sería posible apelar a razones provenientes de doctrinas morales o concepciones particulares del bien; este último sería el espacio de las Iglesias y otra asociaciones (RAWLS, 2001: 158-159).

Según RAWLS, el uso de la razón pública sería consecuencia de un «deber de civilidad» —en ese sentido moral y no legal—, que se presentaría en el supuesto de ejercicio de un poder político, principalmente referido a los funcionarios públicos pero también a los ciudadanos en general, quienes en teoría aprobarían las decisiones adoptadas por

${ }^{10}$ En Liberalismo Político y en trabajos posteriores, RAWLS vuelve sobre la noción de razón pública, advirtiendo que la misma no debe ser confundida con la razón secular, pues ésta última parte de doctrinas generales no religiosas, en tanto que la razón pública se basa en valores políticos y no en doctrinas morales (RAWLS, 2001: 167). 
dichos funcionarios cuando las mismas se sustenten en razones públicas (RAWLS, 1995: 208; 2001: 161):

De ahí que la idea de legitimidad política basada en el criterio de reciprocidad diga: nuestro ejercicio del poder político es apropiado sólo cuando creemos sinceramente que las razones que ofrecíamos para nuestras acciones políticas — si tuviéramos que formularlas como funcionarios públicos- son suficientes, y cuando creemos razonablemente que otros ciudadanos pueden aceptar de manera razonable tales razones (RAWLS, 2001: 161).

HABERMAS, por su parte, ha sostenido que las actuales sociedades post seculares ${ }^{11}$ afrontan un reto que debería ser asumido a partir de una nueva actitud de los sujetos en relación con el valor que tendría el discurso religioso en el ámbito público.

El filósofo alemán habla de un aprendizaje complementario entre ciudadanos religiosos y seculares, que sólo sería posible en la medida que los ciudadanos seculares superen una estrecha conciencia secularista y «abran sus mentes al posible contenido de verdad de las contribuciones religiosas» (HABERMAS, 2006: 140). En su opinión:

[...] el Estado liberal tiene interés en que se permita el libre acceso a las voces religiosas tanto en la esfera público-política como en la participación política de las organizaciones religiosas. El Estado no puede desalentar a los creyentes y a las comunidades religiosas para que se abstengan de manifestarse como tales también de una manera política, pues no puede saber si, en caso contrario, la sociedad secular no se estaría desconectando y privando de importantes reservas para la creación de sentido. [...]

Las tradiciones religiosas están provistas de una fuerza especial para articular intuiciones morales, sobre todo en atención a las formas sensibles de la convivencia humana. Este potencial convierte al habla religiosa, cuando se trata de cuestiones políticas pertinentes, en un serio candidato para posibles contenidos de verdad, que pueden ser traducidos entonces desde el vocabulario de una comunidad religiosa determinada a un lenguaje universalmente accesible (HABERMAS, 2006: 138-139).

De este modo, la admisión del discurso religioso en la esfera pública no sólo debería apreciarse desde los estrechos márgenes de la tolerancia liberal, o incluso a partir del reconocimiento del ejercicio de los derechos a la libertad de conciencia o de expresión - aspectos que aceptaría cualquier liberal, incluso en el caso del racionalista más secularista de todos-, sino que sería bienvenido como un aporte más que enriquecería el debate público, ya sea por el contenido de verdad que pudieran tener las razones religiosas o por su capacidad para promover convicciones morales.

HABERMAS considera que la exigencia de una necesaria traducción de las razones religiosas a razones públicas — requisito defendido por el pensamiento liberal secular para que las razones religiosas puedan ser tomadas en cuenta en el debate públicopuede resultar discriminatoria para el creyente, pues es un requisito que no se le pide al no creyente que participa del debate público. Por eso, a diferencia de RAWLS, la carga

11 «Utilizo esa expresión para describir las sociedades modernas que se encuentran con que siguen existiendo grupos religiosos y que las diferentes tradiciones religiosas siguen siendo relevantes, aunque las sociedades mismas estén en gran parte secularizadas. En la medida en que describo como "postsecular" no la sociedad misma, sino un correspondiente cambio de conciencia en ella, el predicado puede utilizarse también para referirse a una autocomprensión modificada de las ya en buena parte secularizadas sociedades de Europa occidental, Canadá o Australia» (HABERMAS, 2011: 131).

Contra el postsecularismo se ha pronunciado CHIASSONI, para quien el movimiento en favor del retorno de lo religioso en las sociedades occidentales producirá un déficit de racionalidad, de lógica y de libertad individual (CHIASSONI, 2013: 24-25). 
de la traducción la soportarían no sólo los creyentes, sino también los no creyentes (FERRARA, 2007).

El filósofo alemán considera que su propuesta de traducción salvaría tanto la objeción normativa (referida a la supuesta sobre exigencia que se le haría a los creyentes, a quienes se les pediría dejar de lado el lenguaje de sus creencia para ofrecer razones públicas, y que podría estar lesionando su igualdad), como la objeción empírica (referida a la imposibilidad que tendrían muchos creyentes de expresar sus razones religiosas en un lenguaje secular, lo que podría conducir a un desdoblamiento artificial de su conciencia); ambas dirigidas contra la tesis de RAWLS (HABERMAS, 2006: 134; 2011:34) ${ }^{12}$.

No obstante, HABERMAS ha recibido una crítica semejante a la objeción empírica contra RAWLS y es que, como refiere Craig CALHOUN, «no todo lo que los ciudadanos creyentes tienen que decir es «traducible»; lo que no lo es puede ser utilizado en el discurso público informal, pero debe existir un filtro institucional para mantenerlo fuera de la deliberaciones formales de los organismos políticos» (CALHOUn, 2011: 120-121). Paradójicamente, esto provoca que - contra lo que precisamente quería HABERMASel criterio de traducción sea necesariamente asimétrico. Además, parecería basarse en consideraciones de tipo instrumental: «Una llamada a incluir ideas porque son útiles, mientras implícitamente se duda de que puedan ser verdad» (CALHOun, 2011: 121) ${ }^{13}$.

HABERMAS ha sido criticado por permitir el ingreso de las razones religiosas al debate público, concediéndoles un posible valor de verdad y exigiendo una forma de compromiso epistémico tanto a los creyentes como a los no creyentes. Esto y el requisito de la traducción con el que pretende salvar la objeción de la inadmisibilidad de las razones particulares en el debate púbico — debido a su falta de universabilidad_-, provocan que HABERMAS incurra en una serie de contradicciones, según FLORES D'ARCAIS.

En primer lugar, resulta contradictorio con su republicanismo kantiano el hecho de que admita la inserción del lenguaje religioso - derivado de doctrinas comprehensivas y basado en criterios de autoridad - en la esfera pública. Luego, al someterlo al requisito de la traducción, incurre en una nueva contradicción: «El argumento religioso, en suma, es legitimado por Habermas sólo si es traducible en términos no religiosos. [...] Lo que significa, entonces, que el argumento religioso es válido si y sólo si resulta superfluo» (FLORES D'ARCAIS, 2008: 57).

Pero, además, HABERMAS basa su tesis y el compromiso que ésta exige a los creyentes y no creyentes en una suerte de injusticia histórica supuestamente sufrida por

12 «Según esa propuesta, todos los ciudadanos deben tener libertad para decidir si utilizan el lenguaje religioso en la esfera pública. Sin embargo, si lo utilizan tienen que aceptar que el potencial contenido de verdad de las afirmaciones religiosas se debe traducir a un lenguaje universalmente accesible, antes de que puedan entrar en el orden del día de los parlamentos, los tribunales o las instituciones administrativas, e influir en sus decisiones» (HABERMAS, 2011: 35).

13 En ese mismo sentido, José María CARABANTE considera que Habermas hace un uso instrumental de la religión, pues no valora adecuadamente el contenido de verdad que tiene el discurso religioso para un creyente y que supone un compromiso sustancial, no meramente accidental, a su vida (CARABANTE, 2012: 217-219). El uso instrumental de HABERMAS deriva de la utilidad que tendría la religión para contribuir a superar los problemas de las actuales sociedades individualistas, egoístas y consumistas, destinadas a la desintegración. De este modo, la religión aparece como una fuente de solidaridad y compromiso social (CARABANTE, 2012: 212-217). 
los creyentes y que, como vimos, sería consecuencia del pensamiento secular moderno. Según el filósofo: «Visto en términos históricos, los ciudadanos religiosos tuvieron que aprender a adoptar actitudes epistémicas hacia su entorno secular, actitudes que a los ciudadanos seculares ilustrados les han recaído sin esfuerzo» (HABERMAS, 2006: 146) ${ }^{14}$. De ahí que algunos autores se basen en la tesis de HABERMAS para criticar la supuesta falta de igualdad entre creyentes y no creyentes.

Para OlLERO, por ejemplo, refiriéndose ya al modelo de laicidad supuestamente agnóstica, defendida por quienes rechazan el concepto de laicidad positiva, y que, en su opinión, resulta persecutoria de la fe de la mayoría: «(e)l creyente habría de traducir su propuesta a términos agnósticos, pero no viceversa. Habermas ha reaccionado contra este planteamiento, precisamente por detectar en él un atentado a la igualdad impropio de un Estado liberal». Y más adelante: «(H)abría de evitar que la obligada traducción civil de los argumentos religiosos se alíe con una primacía institucional concedida a los argumentos agnósticos, eximiéndolos del esfuerzo de aprendizaje y de adaptación que se impone a los ciudadanos creyentes» (OLLERO, 2009: 213).

La propuesta de HABERMAS, al otorgar un rol protagónico a la religión (al discurso religioso), pretende poner de manifiesto la visión limitada del secularismo moderno y reconocer la importancia de la dimensión espiritual del ser humano; sin embargo, abre también una peligrosa vía para el fortalecimiento de las instituciones religiosas - representadas por sus líderes o voceros oficiales - en el escenario público ${ }^{15}$. Contra lo que querría el propio autor, eventualmente podría servir también como argumento para justificar actitudes contrarias al principio de laicidad del Estado. Por ejemplo, cuando se demanda una mayor presencia de la Iglesia en el escenario público, mediante la promoción estatal de sus actividades o manifestaciones, al considerarlas como un elemento valioso de la deliberación pública ${ }^{16}$.

En defensa de HABERMAS, habría que decir que él no considera que las razones religiosas (o el lenguaje religioso) estén habilitadas para participar en cualquier escenario

14 Al contrario, FLORES D'ARCAIS considera que la supuesta asimetría de la que habla HABERMAS no es real, pues es consecuencia de adoptar un sistema democrático: «Ese "esfuerzo de aprendizaje y de adaptación exigido a los ciudadanos religiosos", que quede claro, no es algo que se "ahorran los ciudadanos laicos". Es irrenunciable para la democracia, y por tanto se le exigiría también a un ateo que considerase "ley de la $\mathrm{Na}$ turaleza" un vitalismo depredador con connotaciones racistas, o que afirmara que la homosexualidad es una enfermedad, o que predicara la eliminación de los disminuidos» (FLORES D’ARCAIS, 2008: 58).

15 Amartya SEN es especialmente crítico con lo que considera una peligrosa tendencia actual a hablar de diálogo interreligioso y a que se convierta a los grupos religiosos en voceros de sus comunidades o culturas, dejándose de lado los intereses particulares que pueden tener los individuos y los movimientos no religiosos o seculares. El autor tiene algunas reflexiones reveladoras acerca del poder que están adquiriendo los grupos religiosos como portadores de la voz de los individuos y sus implicancias en el retroceso del secularismo, la consolidación de la concepción unidimensional del individuo, la pérdida de perspectiva de las diferencias dentro de los propios grupos, entre otras. Así pues, hoy se advierte una exaltación de la voz de las autoridades religiosas que ha llevado a que «(a) pesar de nuestras diversidades diversas, de repente el mundo ya no es visto como un conjuntos de personas, sino como una federación de religiones y civilizaciones» (SEN, 2007: 37).

16 Nos parece que en ese sentido va también OlLERO cuando critica las medidas dirigidas a excluir el juramento y los símbolos religiosos en los espacios públicos (por considerarse violatorios del principio de laicidad o del derecho a la igualdad). Acudiendo a un recurso retórico OlleRo sostiene: «No ha faltado quien comente que, a este paso, el creyente sólo podrá jurar en arameo. En pocas circunstancias es más directamente aplicable la denuncia habermasiana: se prohíbe al creyente comportarse como tal, sin perjuicio conocido para un agnóstico que impone por decreto su propia convicción» (OLLERO, 2009: 215). 
público. Así pues, él hace una distinción entre el espacio institucional y el espacio de la sociedad civil. Por eso sostiene:

Debemos diferenciar, por supuesto, de manera clara los procesos institucionalizados de deliberación y toma de decisiones en el nivel de los parlamentos, tribunales, ministerios y autoridades administrativa del compromiso informal de los ciudadanos en la sociedad civil y en la esfera pública [...].

En el Estado constitucional es una exigencia de legitimación que las decisiones políticas aplicables por el Estado se formulen en un lenguaje que todos los ciudadanos puedan comprender (HABERMAS, 2008: 6) ${ }^{17}$.

Asimismo, el compromiso de comunicación y aprendizaje mutuo, del que debieran participar tanto los ciudadanos laicos como los religiosos, no implica la pérdida del pensamiento postmetafísico ${ }^{18}$ ni elimina la distinción entre fe y conocimiento como formas esencialmente diferentes de pretensión de verdad. La sociedad postsecular, en los términos que él propone, sólo implicaría una relación hasta ahora no existente entre la razón secular y una conciencia religiosa reflexiva (HABERMAS, 2011: 133).

\section{EL SENTIDO DE LA LAICIDAD DEL ESTADO}

La laicidad constituye «una forma de organización político-social que busca la neutralidad del Estado frente a la religión, garantizando la libertad e igualdad de las personas» (ABAD, 2012: 19). De este modo, el principio de laicidad cobra sentido no como un fin en sí mismo, sino en relación con los derechos que garantiza y promueve. Como explica PRIETO:

La libertad y la igualdad religiosa son ante todo derechos fundamentales de carácter subjetivo [...]. Pero la laicidad es un principio exclusivamente objetivo, conectado por tanto al modo de ser y de actuar de las instituciones públicas; no existe un derecho fundamental a la laicidad que pueda ser esgrimido por los ciudadanos. Y, sin embargo, pese a ello intentaré mostrar que la laicidad representa una condición de la libertad de creencia y, sobre todo, de la igualdad de los individuos cualesquiera que sean sus creencias (PRIETO, 2013: 247).

Según MACLURE y TAYLOR, la falta de claridad sobre los derechos que pretende garantizar el principio de laicidad ha provocado una confusión entre los medios y los fines de la laicidad. Como señalan los autores:

No todos los principios de la laicidad son del mismo tipo. La igualdad de trato y la libertad de conciencia son principios morales cuya función es regular nuestro comportamiento (o, en el caso que nos ocupa, la acción del Estado), mientras que la neutralidad, la separación y el acomodamiento son lo que podríamos denominar «principios institucionales» derivados de los principios de igualdad de trato y libertad de conciencia. [...] El valor de los «principios institucionales» es derivado más que intrínseco; son medios fundamentales para la realización de fines propiamente morales (MACLURE y TAYLOR, 2011:38).

17 Para una crítica a lo que considera una distinción artificial entre el plano institucional (ámbito estrictamente político-estatal) y no institucional (ámbito de la opinión pública), vid. FLORES D’ARCAIS, 2008: 57-58.

18 Así pues: «El pensamiento postmetafísico está dispuesto a aprender de la religión al tiempo que permanece estrictamente agnóstico en sus relaciones con ella. Insiste en la diferencia entre las certezas de fe y las pretensiones de validez públicamente criticables, pero se abstiene de la arrogancia racionalista de que puede él mismo decidir qué es lo razonable y qué lo irrazonable en las doctrinas religiosas» (HABERMAS, 2006: 151). 
En ocasiones, el erróneo tratamiento de los medios y los fines de la laicidad ha derivado en una suerte de fetichismo de los medios, enfatizándose el discurso de la laicidad (la separación de la Iglesia y el Estado y la neutralidad del Estado) como fin en sí mismo, e incluso sacrificándose los principios morales que garantiza (MACLURE y TAYLOR, 2011: 45). Por ejemplo, en el caso de la discusión en torno a los velos en Francia en el que la laicidad del Estado fue entendida como un valor que debía prevalecer sobre la libertad de conciencia de las mujeres musulmanas ${ }^{19}$.

En ese sentido, es importante reconocer a la laicidad como un principio que debe ser ponderado a la luz de las circunstancias del caso concreto y en atención a los derechos de libertad e igualdad que lo justifican. Desde la reflexión filosófica, MACLURE y TAYLOR acercan el tratamiento de la laicidad —entendida como principio ponderable y no como regla, de aplicación todo o nada - a la forma en que el derecho del Estado constitucional concibe la aplicación de los principios.

Volviendo a sus orígenes, el desarrollo del principio de laicidad en el Estado de derecho moderno sirvió para consolidar una concepción liberal de los derechos (como veremos, en términos más negativos que positivos) y —en la línea del pensamiento liberal - la neutralidad estatal frente a las concepciones éticas o religiosas particulares. El mecanismo que la doctrina liberal utilizó para lograr dicha neutralidad fue el de la separación entre Estado e Iglesia(s), destacándose dos momentos o modelos separatistas: el norteamericano y el francés (CHIASSONI, 2013: 18-22). No obstante, el francés puede calificarse, más bien, como un modelo de tipo republicano (asociado a la idea de religión civil de ROUSSEAU) ${ }^{20}$, y que, en ocasiones, puede llegar a ser profundamente antiliberal por su falta de reconocimiento de derechos individuales ${ }^{21}$.

Para PRIETO la concepción liberal de la laicidad, al contrario que la republicana, sería la mejor forma de interpretar dicho principio, pues garantizaría efectivamente los derechos de libertad y de igualdad y apostaría por una concepción deliberativa amplia. De este modo, ingresarían al debate público las diferentes «verdades» (religiosas o seculares) en condiciones de libertad e igualdad, en los términos en que por ejemplo RAWLS lo propone en su Liberalismo Político (PRIETO, 2013: 253).

A diferencia de la tesis liberal, la republicana sí apuesta por un compromiso con ciertos valores y virtudes políticas o cívicas (no morales, en sentido estricto) ${ }^{22}$. No obs-

19 Sobre el caso, dicen MACLURE y TAYLOR: «Prohibir que una profesora lleve el biyab acentúa la aparente neutralidad de la institución escolar, pero limita su libertad de conciencia y de culto, o pone en peligro el principio de igualdad de oportunidades cerrándole las puertas de una carrera gracias a la cual podría haber contribuido a la sociedad» (MACLURE y TAYLOR, 2011: 40).

20 Cfr. PRIETO, 2013: 251-253; Rey, 2005: 49, 61.

21 En ese sentido también, P. RIVAS PALÁ (citado por REY) considera que el principio de laicidad francés sería un tipo de fundamentalismo incompatible con los principios de una sociedad liberal y con el pluralismo que ésta reconoce (REY, 2005: 49-50). De ahí que resulten de tan difícil solución los problemas de integración en un contexto multicultural, pero marcadamente republicano, como el francés. O que, como señala REY, la laicidad en Francia se entienda como «puro nacionalismo francés con disfraz» (REY, 2005: 61).

22 Al respecto, QuESADA recuerda la distinción que hace MONTESQUIEU en Del Espíritu de las Leyes: «Y eso nuevo de que habla es la virtud, la virtud política, un nuevo campo normativo que hemos de diferenciar de la virtud ética o de la moral religiosa. La virtud referida a la República consiste en "el amor a la patria, el amor a la igualdad" [...].

El amor a la patria no estriba en una simple solidaridad de los individuos en tiempos difíciles o circunstancias adversas, como puede ser la intrusión de un enemigo en nuestro país. El amor a la paria traduce, por el 
tante, es importante subrayar que existen diferencias entre las posiciones republicanas y que el modelo francés no puede ser identificado como el paradigma del modelo republicano.

Hay autores que pueden ser cercanos al republicanismo - pues reconocen la importancia de los valores cívicos y del compromiso político de los individuos en una comunidad- pero, sin embargo, tienen claro que los objetivos republicanos no pueden realizarse a costa de los derechos individuales, y en ese sentido son autores liberales. Así, por ejemplo, Nussbaum cuando defiende la existencia de los cursos de educación para la ciudadanía ${ }^{23}$, pero no la decisión francesa de prohibir el uso del velo islámico en las escuelas públicas (NussBaum, 2011: 77-79).

En el contexto de los actuales Estados constitucionales de derecho, a los derechos individuales de libertad e igualdad se suma la garantía del pluralismo como uno de los rasgos definitorios del Estado constitucional. Por esa razón, autores como MACLURE y TAYLOR abogan por un modelo de laicidad liberal-pluralista (MACLURE y TAYLOR, 2011: 50-51). No obstante, la garantía del pluralismo - principalmente en el caso del pluralismo cultural, representado por demandas de minorías, pero también en el caso del pluralismo ético individualista-, puede significar un dilema para la supervivencia del principio de laicidad.

Algunas propuestas multiculturalistas han derivado en demandas dirigidas al Estado, a fin que éste actúe no sólo como garante sino también como promotor del pluralismo. Esa función promotora, en lo que respecta a la identidad religiosa, podría producir, sin embargo, un retroceso en el modelo secular y en el principio de neutralidad que está en la base del Estado liberal laico; además, supondrían un peligro para la afirmación de los derechos individuales (principalmente en el caso de los ateos o agnósticos) que puedan entrar en conflicto con las demandas de los grupos religiosos.

Esta tensión se ve reflejada, por ejemplo, en la discusión en torno al valor del pluralismo y la opción a favor de un laicismo republicano en Francia (REY, 2005: 44). Pero también tiene que ver con la discusión acerca de la pertinencia (tanto en términos pragmáticos como jurídicos) de una dimensión positiva del principio de laicidad y de los mecanismos de cooperación o colaboración con las iglesias que esa propuesta conlleva.

Nosotros creemos que la mejor forma de hacer frente a los conflictos que presentan las sociedades seculares y plurales del Estado constitucional sería mediante una concepción liberal, no necesariamente incompatible con ciertos modelos republicanos —al modo en que por ejemplo lo entiende RAWLS (RAWLS, 2002: 196) — ni tampoco con el pluralismo que, sin embargo, tendrá como límite el respeto de los derechos de libertad e igualdad del individuo, que son los que precisamente justifican el ideal del Estado laico.

contrario, las virtudes que dan o proporcionan cohesión social, que asientan y dan contenido a la idea de bien común como contexto en el que se apoyan y vivifican las libertades de los individuos» (QUESADA, 2005: 67).

23 En el mismo sentido GarCía Figueroa, 2007. 


\section{EL PROBLEMA DE LA LAICIDAD POSITIVA Y EL PRINCIPIO DE COLABORACIÓN CON LA IGLESIA}

La distinción entre libertad negativa y libertad positiva fue propuesta por Isaiah BERLin en su conocido texto Dos conceptos de libertad (BERLIN, 2005). Según el concepto de libertad negativa la libertad es entendida como la acción plena del sujeto frente al Estado o cualquier otra fuerza que impida u obstaculice su acción (o que lo obligue a hacer aquello que va más allá de su voluntad). El concepto de libertad positiva, en cambio, está vinculado a la idea de autonomía y a la posibilidad de que, en términos reales, un sujeto pueda actuar libremente, conforme a su voluntad y no condicionado por las fuerzas o limitaciones del entorno (por ejemplo, por las necesidades económicas, la dominación ejercida por otros, etc.).

A partir del concepto de libertad positiva, se considera que es deber del Estado contribuir al desarrollo de ciertas capacidades de los sujetos, que permitan su desarrollo como individuos autónomos. Frente a una estrecha concepción de la neutralidad del Estado (que parte de la noción de Estado mínimo), se defiende una dimensión garantista e incluso promotora que contribuya a eliminar los obstáculos derivados de la falta de recursos económicos, educación o salud, la marginalidad, la discriminación, entre otros.

La libertad religiosa también puede ser entendida como una libertad de tipo negativa o positiva. La consecuencia de asumir una concepción positiva de este derecho es la atribución de una función promotora, no sólo facilitadora, de este derecho por parte del Estado; lo que coincidiría con el sentido de los convenios de colaboración o cooperación que se establecen con ciertas religiones. Sin embargo, esto supone un dilema para el principio de laicidad, pues se deberá elegir entre el respeto a la estricta neutralidad estatal — que impediría cualquier forma de promoción o auspicio de alguna religión o del fenómeno religioso, entendido como algo valioso- $-\mathrm{y}$, de otro lado, la idea de un Estado promotor de la dimensión positiva de la libertad religiosa. La solución propuesta por una parte de la jurisprudencia y de la doctrina — que también sigue el Tribunal Constitucional peruano- es apostar por un concepto de laicidad positiva que, en nuestra opinión, es muy cuestionable y puede terminar vulnerando los derechos de libertad y de igualdad que, precisamente, pretende garantizar el principio de laicidad.

En relación con el denominado principio de cooperación con la Iglesia católica éste está reconocido en el art. 16.3 de la Constitución española ${ }^{24}$ y, de forma similar, en el art. 50 de la Constitución peruana ${ }^{25}$.

Como refiere REVILLA, este principio representa el compromiso que tiene el Estado de «facilitar y promover las condiciones que hacen posible el acto de fe y los

24 Art. 16.3: «Ninguna confesión tendrá carácter estatal. Los poderes públicos tendrán en cuenta las creencias religiosas de la sociedad española y mantendrán las consiguientes relaciones de cooperación con la Iglesia Católica y las demás confesiones».

$25 \mathrm{El}$ art. 50 de la Constitución peruana señala:

«Dentro de un régimen de independencia y autonomía, el Estado reconoce a la Iglesia Católica como elemento importante en la formación histórica, cultural y moral del Perú, y le presta su colaboración.

El Estado respeta otras confesiones y puede establecer formas de colaboración con ellas». 
diversos aspectos o manifestaciones que derivan del mismo» (REVILLA, 2013: 458), a través de su relación con los sujetos colectivos de la libertad religiosa (Iglesias o entidades religiosas a las que, por ejemplo, alude la Ley de Libertad Religiosa peruana) ${ }^{26}$. El principio de cooperación o colaboración sería una consecuencia de «la proyección en el ámbito del derecho eclesiástico de los postulados del llamado Estado social y, en particular de la concepción promocional de los derechos humanos» (REVILLA, 2013: 459) ${ }^{27}$, en consonancia con la idea de libertad positiva que venimos explicando.

Quienes defienden una laicidad positiva, basada en el concepto de cooperación o colaboración con la Iglesia, no sólo resaltan la influencia que tiene la Iglesia católica en la historia de nuestras naciones - el argumento de la tradición al que alude REY (REY, 2011: 13)—, sino el hecho de que corresponde a la fe de la mayoría —el argumento supuestamente democrático (REY, 2011: 13)—, así como también la labor social que cumple la Iglesia en el ámbito de la salud o la educación, por ejemplo ${ }^{28}$.

No obstante, lo cierto es que resulta complejo defender una forma de laicidad positiva bajo el argumento de la libertad positiva que lo que busca es remover los obstáculos sociales o materiales que impiden una libertad real, cuando de lo que se habla es de acciones a favor de un colectivo que ocupa una posición dominante en la sociedad (no sólo por su historia, sino porque representa a la mayoría de los ciudadanos). Como dice Ruiz MigueL:

[...] la aplicación de la noción de «acción positiva» a las ayudas a la Iglesia católica constituye una clara inversión de tal noción, sino también una perversión, en cuanto que en su caso consisten en ayudas a un grupo mayoritario que no ha venido sufriendo discriminación ni desventaja alguna, sino más bien todo lo contrario, y cuyo objetivo no es conseguir la igualdad social entre las creencias religiosas sino mantener, e incluso aumentar, el predominio sociológico de que viene gozando (Ruiz Miguel, 2009: 165).

Para el autor, sólo la libertad religiosa en sentido negativo sería acorde con una verdadera concepción laica del Estado. Al contrario, la apertura a una dimensión positiva de dicho derecho conduce a una tendencia comunitarista y antiliberal, en la medida que termina poniéndose énfasis en la comunidad (Iglesia, entidad religiosa, etc.) y no en el individuo (Ruiz Miguel, 2009: 44).

En relación con el rol prestacional del Estado, dice el autor: «"la medida y proporción" en la que se puede reclamar el derecho a la libertad religiosa como prestación depende de que exista una comunidad y de su relativa implantación», luego, esto

26 El art. 15 de la Ley de Libertad Religiosa (Ley 29635) establece que el Estado peruano puede suscribir convenios de colaboración sobre temas de interés común «con aquellas entidades religiosas que, estando inscritas en el registro a que se refieren los artículos precedentes [el Registro de Entidades Religiosas], hayan adquirido notorio arraigo con dimensión nacional y ofrezcan garantías de estabilidad y permanencia por su número de miembros y actividades».

27 En términos de PRIETO: «El tránsito al Estado social parece haber supuesto una cierta mutación en el tratamiento de la libertad de conciencia: si en el Antiguo Régimen inspirado en la confesionalidad o en el modelo de la religión de Estado la intolerancia significaba una discriminación negativa o penal de las minorías, y frente a ese estado de cosas luchó precisamente la filosofía de la tolerancia, ahora la diferencia de trato se cifra en una discriminación positiva de las mayorías» (PRIETO, 2013: 256).

28 NAVARRO-VALLS se ha referido a la inversión de la Iglesia católica en colegios, hospitales, casas de ancianos y centros para la infancia, que representaría un ahorro considerable para el denominado Estado de bienestar. Por esa razón, en su opinión, la cooperación tendría que ser vista como un concepto que va en ambas direcciones y no sólo del Estado hacia la Iglesia (NAVARRO-VALLS, 2009: 138-145). 
afectaría el derecho a la igualdad, pues «resulta que mientras la igualdad en la libertad religiosa negativa es real y efectiva para los individuos con la mera garantía por parte del Estado de la no interferencia ajena, la igualdad en la libertad religiosa como poder, a través de prestaciones, sólo puede ser real y efectiva para las comunidades [...]» (RUIZ MigUEL, 2009: 43-44).

Al contrario, OlLERO afirma que lo correcto en el caso de los no creyente es, en efecto, contar con una libertad religiosa de tipo negativa, que no podría ser positiva en forma alguna pues ello supondría que el Estado auspicie dicha creencia (o no creencia). Según el autor: «Convertir el agnosticismo en confesión religiosa ya suena paradójico; reclamar para ella el principio de cooperación bordea el esperpento» (OLLERO, 2009: 207).

Compartimos lo dicho por RuIz Miguel, en el sentido de que las acciones derivadas de la concepción positiva de la laicidad muestran una tendencia comunitarista de corte antiliberal, en la medida que pueden afectar derechos individuales, esencialmente la igualdad de trato. OLLERO, en cambio, incurre en un argumento falaz al identificar la neutralidad que se le exige al Estado con una suerte de adhesión al ateísmo o al agnosticismo. Lo que precisamente se exige en virtud del principio de laicidad es que el Estado no patrocine manifestaciones vinculadas a las creencias religiosas (pero también antirreligiosas) de cierta parte de la población. Pedir que se abstenga de ello no supone adoptar una concepción atea, sino neutral.

Por ilustrarlo con un ejemplo: es posible acompañar a quien reza (compartir su fe), mantener una prudencial distancia respecto de él (la distancia de quien ni comparte ni rechaza, pero respeta) o también es posible prohibir al que reza que lo haga. El punto en el que se encontraría el Estado laico es el segundo y no el tercero. El hecho de que el Estado no facilite el lugar, los elementos necesarios o el momento para que se produzca dicho acto de fe no lo vuelven un Estado agresivo respecto del fenómeno religioso, pues no es parte de su labor facilitar esos medios, sino de quienes pertenecen a esa fe (más todavía si está institucionalizada) y que en sus iniciativas de organización sí deberían contar con las facilidades estatales para su adecuada organización y funcionamiento (agilización en el trámite de licencias de construcción de edificios destinados al culto o de su constitución como asociaciones, por ejemplo).

Decir, como hace OlLERO, que a los ateos y agnósticos sólo les toca una libertad negativa, mientras que los creyentes (y, en los hechos, los creyentes de la fe mayoritaria) sí tienen una libertad positiva y las ventajas derivadas de la actuación promocional de la misma (muchas veces subvencionadas por el dinero de los propios no creyentes) resulta discriminatorio.

Estamos de acuerdo con la Corte Constitucional colombiana cuando sostiene que, cuando hablamos de laicidad, es importante hacer una clara distinción entre una igualdad de oportunidades — de manera que es posible exigir a un Estado laico que garantice que todas las religiones tengan las mismas oportunidades y desarrollen sus actividades en plena libertad (lo que sería consecuencia del derecho a la libertad de conciencia, religión y culto $)^{29}$ - y una igualdad de resultado, que no es función del Estado laico

29 En ese sentido serían correctas algunas de las llamadas medidas de acomodamiento a favor de los individuos que forman parte de ciertas minorías religiosas. Como recuerdan MACLURE y TAYLOR estas medidas tienen 
garantizar y que es, precisamente, lo que conduciría a pensar que es deber del Estado promover a todas las religiones por igual. En palabras de la Corte:

La neutralidad, derivada de la laicidad, no consistirá en la búsqueda por parte del Estado de un tratamiento igual a las religiones a partir de las actividades que éste realice en relación con ellas. La neutralidad estatal comporta que las actividades públicas no tengan fundamento, sentido u orientación determinada por religión alguna —en cuanto confesión o institución-, de manera que las funciones del Estado sean ajenas a fundamentos de naturaleza confesional. En este sentido, la igualdad no se logra motivando las funciones estatales con base en intereses de todas las religiones por igual —algo, por demás, de imposible realización en la práctica-, pues esta pretendida igualdad, en cuanto vincula motivos religiosos en las actividades estatales, sería diametralmente contraria al principio de secularidad que resulta ser el núcleo del concepto de laicidad estatal y, de su concreción, el principio de neutralidad ${ }^{30}$.

\section{EL CASO PERUANO: COLABORACIÓN Y ESPECIAL CONSIDERACIÓN DE LA IGLESIA CATÓLICA}

La vinculación entre el Estado peruano y la Iglesia católica quedó establecida desde inicios de la República ${ }^{31}$. La primera Constitución de 1823 no hizo sino confirmar el carácter confesional del Estado peruano y a lo largo de las varias Constituciones que siguieron a ésta se fue pasando de una marcada confesionalidad al respaldo expreso a la religión católica ${ }^{32}$.

Con el fin del gobierno militar y la dación de la Constitución de 1979, el Patronato Nacional fue derogado para dar paso a un sistema de independencia y autonomía estatal. Aunque con la Constitución de 1979 se buscó adoptar un modelo de Estado laico, nació también una nueva obligación para el Estado peruano: el deber de cooperación. Este compromiso se consolidó con la firma del Concordato de 1980, por el cual el Estado peruano se obliga a prestar su colaboración a la Iglesia católica ${ }^{33}$.

su fundamento en las políticas de reconocimiento de minorías tradicionalmente excluidas y han sido pensadas para corregir problemas derivados de la falta de neutralidad de determinadas normas jurídicas que se aplican a todos los ciudadanos de un Estado y que, por razones prácticas, resultan inevitables, pues como dicen los autores: «Hay normas que simplemente no pueden ser culturalmente neutrales» (MACLURE y TAYLOR, 2011: 90). Por ejemplo, la que establece el domingo como día de descanso.

También NussBAum se ha referido a este tipo de medidas como una suerte de remedios frente a la concepción liberal tradicional (lockeana) de la libertad religiosa y su supuesta neutralidad, que puede derivar en formas sutiles e involuntarias de discriminación (NuSSBAUM, 2013: 95-119).

30 Sentencia C-766/10, de 22 de septiembre de 2010, 29.

31 Es así que en el art. 16 del Reglamento Provisional de Huaura, dado por José de San Martín en febrero de 1821, se dispuso reasumir la figura del Patronato, a través del cual la Santa Sede reconocía ciertas tareas de evangelización al Estado peruano (ABAD, 2012: 42). Las relaciones entre el Estado y la Iglesia católica se vieron reforzadas también por el Estatuto Provisional del 8 de octubre de 1821, por el cual San Martín instituyó como religión del nuevo Estado peruano a la católica.

32 Para un desarrollo de este proceso, vid. ABAD, 2012: 42-62.

33 No obstante, tanto la Constitución de 1979 como la de 1993 abren la posibilidad de suscribir convenios de colaboración con otras confesiones. Ello ha sido recogido en la Ley núm. 29635, Ley de Libertad Religiosa, y en su reglamento. En razón de estos cuerpos normativos, promulgados entre diciembre de 2010 y julio de 2011, el deber de colaboración deja de ser exclusivo de las relaciones entre la Santa Sede y el Estado peruano, para incluir a otras confesiones que cumplan con algunos requisitos, como su inscripción en los registros gubernamentales, el contar con determinado número de fieles y su carácter de estabilidad y permanencia. 
Formalmente, el Concordato es un tratado internacional celebrado por sujetos de derecho internacional (entre los que se encuentran los Estados, las organizaciones internacionales y, con un estatuto especial, la Iglesia católica), al que se le aplican las normas del derecho internacional público. Lo cierto, sin embargo, es que el acuerdo con la Santa Sede ha significado un conjunto de beneficios a favor de la Iglesia católica que se traducen en aspectos como los siguientes: subvenciones, exoneraciones y beneficios tributarios; reconocimiento de la asignatura de religión como materia ordinaria en el currículo escolar (a efectos de su efectiva implementación en las escuelas públicas, el nombramiento de los profesores de religión estará a cargo del obispo), aunque la ley establece que los padres pueden pedir que sus hijos sean exonerados de dicha materia por razones de conciencia; existencia de vicarios castrenses y de servicios religiosos para los fieles en centros hospitalarios, tutelares y penitenciarios.

El Tribunal Constitucional peruano ha sostenido que el concepto de colaboración que incorpora el texto constitucional nos sitúa en un modelo intermedio, ni de unión ni de separación absoluta entre el Estado y las confesiones religiosas ${ }^{34}$. Asimismo, ha defendido la dimensión positiva de la libertad religiosa ${ }^{35}$.

En la sentencia que resolvió el expediente núm. 06111-2009-PA/TC (caso en el que se discutía la presencia del crucifijo y la Biblia en las salas judiciales y despachos de magistrados), el Tribunal consideró que en tanto el Estado no coaccione ni concurra con la fe y la práctica religiosa, «por mucha actividad de reconocimiento, tutela y promoción del factor religioso que desarrolle, se comportará siempre como Estado laico» (fundamento 25). Asimismo, resaltó el valor cultural e histórico de la religión católica, señalando que «la Constitución, junto con el principio de laicidad del Estado, considera importante el componente religioso perceptible en la sociedad peruana» (fundamento 29) y recordó lo dicho en una sentencia anterior, en el sentido de que: «No puede soslayarse que la religión católica ha sido y es la fe tradicional del pueblo peruano - la cual por varias razones se articula a nuestro concepto mismo de nación[...]» (expediente núm. 3283-2003-AA/TC, fundamento 23).

En el caso, el Tribunal Constitucional peruano consideró legítima la presencia de los símbolos de la religión católica (el crucifijo y la Biblia), en las salas y despachos judiciales a nivel nacional, arguyendo el valor cultural, no necesariamente religioso, de los mismos. A partir de lo que, creemos, constituye una concepción distorsionada de la laicidad del Estado, sostuvo que aunque el principio de laicidad define al Estado como radicalmente incompetente ante la fe:

no significa que, con la excusa de la laicidad, pueda adoptar una actitud agnóstica o atea o refugiarse en una pasividad o indiferentismo respecto del factor religioso, pues, en tal caso, abandonaría su incompetencia ante la fe y la práctica religiosa que le impone definirse como Estado laico, para convertirse en una suerte de Estado confesional no religioso. Así, tanto

34 Fundamento 31 de la sentencia recaída en el expediente núm. 06111-2009-PA/TC.

35 «La libertad religiosa, como toda libertad constitucional, consta de dos aspectos. Uno negativo, que implica la prohibición de injerencias por parte del Estado o de particulares en la formación y práctica de las creencias o en las actividades que las manifiesten. Y otro positivo, que implica, a su vez, que el Estado genere las condiciones mínimas para que el individuo pueda ejercer las potestades que comporta su derecho a la libertad religiosa» (fundamento 15 de la sentencia recaída en el expediente núm. 0256-2003-HC/TC). 
puede afectar a la libertad religiosa un Estado confesional como un Estado «laicista», hostil a lo religioso (fundamento 28 ).

De este modo, el Tribunal consideró que la prohibición del crucifijo y la Biblia en las salas y despachos judiciales sería una forma de persecución del fenómeno religioso y algo así como una suerte de promoción del ateísmo o el agnosticismo ${ }^{36}$.

De forma similar piensa OLLERO, quien cree que hoy en día (en España) se presentan formas de discriminación contra los creyentes, producto del pensamiento laicista que considera que las creencias religiosas entorpecen el debate público al estar privadas de racionalidad y que, por tanto, deberían estar circunscritas al ámbito privado (Ollero, 2007: 275). El profesor español considera que la laicidad positiva, reconocida por el Tribunal Constitucional español, permitiría desechar una interpretación, según él, laicista, y optar por un modelo de Estado comprometido con la neutralidad, pero también «al servicio de una sociedad que no es neutra ni, en la medida que se respete su pluralismo, tiene por qué verse neutralizada» (OLLERO, 2007: 270).

Podría ser atendible la crítica de OLLERO cuando se refiere al desprecio con que el laicismo ha visto a las creencias religiosas y que obedece a la visión del secularismo moderno — deudor del pensamiento racionalista y cientificista de la modernidad - al que nos referimos en la primera parte de este trabajo. Sin embargo, revalorar la dimensión espiritual del individuo en las sociedades postseculares —concediéndoles el respeto y consideración debida a las creencias religiosas, que le permiten al sujeto alcanzar objetivos distintos a los que podría lograr a través de la ciencia u otro tipo de conocimiento-, no supone admitir la validez, ni siquiera la intromisión, de los argumentos religiosos o de las manifestaciones religiosas en el ámbito público.

El propio HABERMAS — a quien cita el autor (OLLERO, 2007: 275) — ha afirmado que en el espacio público institucional debe mantenerse «un lenguaje que todos los ciudadanos puedan comprender» (HABERMAS, 2008: 6). De este modo, contrariamente a lo que querría la Iglesia, aspectos como la discusión en torno a la denominada unión civil entre personas del mismo sexo pueden ser libremente debatidos en el ámbito de la sociedad civil, incluso bajo razones religiosas — si se quiere, incluso mediante argumentos intraducibles y no universalizables ${ }^{37}$ - , pero ese tipo de razones no pueden ni

36 «El hecho de que exista una neutralidad del Estado en materia religiosa no significa que los poderes públicos hayan de desarrollar una especie de persecución del fenómeno religioso o de cualquier manifestación de tipo religiosa.

La laicidad es incompatible con un Estado que se considere defensor o protector de una determinada confesión, pero también lo es con un Estado que promueva el ateísmo o el agnosticismo o el destierro del ámbito público de toda expresión de origen religioso. La incompetencia del Estado ante la fe y la práctica religiosa no significa la promoción del ateísmo o agnosticismo con la eliminación de símbolos religiosos de la esfera pública o la imposición de una ideología antirreligiosa, ignorando las tradiciones que responden a la formación histórica, cultural y moral del Perú» (fundamento 49).

37 Con base en una concepción amplia de debate público, serían admisibles incluso las pancartas colocadas en varias calles de Lima por cierto movimiento religioso evangélico, no obstante haber sido consideradas por algunos como una forma de discriminación o de lenguaje de odio. Un diario de la capital da cuenta de la demanda interpuesta por un joven homosexual contra el Movimiento Mundial Bethel, por la colocación de paneles en contra de la unión civil, que, en su opinión promueven la violencia contra la comunidad LGTB (lesbianas, gays, bisexuales y transexuales) y atentan contra el derecho del consumidor a no ser discriminado (arts. 1 y 38 del Código de Protección y Defensa del Consumidor). En dichos paneles aparecían frases bíblicas, como la siguiente: «No te echarás con varón como con mujer; es abominación» (Levítico 18:22). La información ha sido 
deben ser llevadas al espacio público institucional (al Congreso, por ejemplo, como ha ocurrido en los debates realizados en la Comisión de Justicia y Derechos Humanos a propósito de la propuesta de la ley de unión civil en el Perú) ${ }^{38}$.

Por tanto, resulta erróneo presentar a la laicidad como laicismo y, de este modo, oponerla a la laicidad positiva. La laicidad liberal bien entendida — que es un principio al servicio de los derechos de libertad y de igualdad de todos los sujetos-, cuando no es concebida dogmáticamente (sino que está abierta a la ponderación en los casos concretos), supone en principio la neutralidad del Estado frente a las creencias religiosos, que no le toca auspiciar ni promover. Y no promover, no es igual a perseguir.

Contrariamente a lo que dice el Tribunal Constitucional peruano en el sentido de que «por mucha actividad de reconocimiento, tutela y promoción del factor religioso que desarrolle [el Estado], se comportará siempre como Estado laico» (fundamento 25 de la sentencia recaída en el expediente núm. 06111-2009-PA/TC), nosotros creemos que en casos como estos, en los que se admite la presencia de los símbolos de una fe particular en el ámbito público institucional (juzgados, salas judiciales o despachos judiciales), el Estado emite un mensaje de respaldo en nada neutral y, con ello, deja de comportarse como un Estado laico.

Pero además, como bien apunta REY en un artículo referido al caso —en el que analiza los argumentos, a veces contradictorios, esgrimidos por el Tribunal Constitucional- el argumento de la tradición que resalta el significado histórico-cultural de los símbolos en cuestión, los cuales en teoría habrían perdido buena parte de su significado religioso para tornarse símbolos culturales, no parece convincente. Según REY, en opinión que compartimos, en el caso del crucifijo no estaríamos ante una tradición religiosamente neutra, como sí lo sería el reconocimiento del domingo como día de descanso, la inclusión de los símbolos religiosos en algunas banderas ${ }^{39}$ o el nombre religioso de ciertas calles o ciudades (REY, 2011: 13-15).

Como sostuvo la Corte Constitucional colombiana en el caso de la objeción presidencial al Proyecto de Ley de Honores que Exalta como Ciudad Santuario al Municipio de la Estrella Antioquía, en este tipo de casos debería evaluarse el carácter predominantemente cultural de la manifestación concreta. En la sentencia se recuerda cómo en una anterior al evaluar la constitucionalidad del descanso laboral dominical y de los días festivos nacionales, provenientes de la tradición católica, la Corte consideró que aunque en su origen tuvieron raíces religiosas, hoy priman elementos culturales propios de la sociedad colombiana, de manera que hubo una evolución desde el rito religioso y el compromiso del Estado con la Iglesia hacia «motivaciones de carácter laico, que buscan asegurar el esparcimiento, el gozo, el descanso de los asociados, o la previsión social de

extraída de la siguiente página web: bttp://diario16.pe/noticia/49643-joven-demanda-bethel-colocacion-panelescontra-union-civil. Visitada el 20 de julio de 2014.

38 En ese contexto, el congresista Julio Rosas sostuvo lo siguiente: «La familia es una institución natural establecida por el Creador, se quiera o no aceptar, se crea o no se crea...». «Por tanto la familia viene a ser sagrada». Video disponible en $h t t p: / / w w w$.youtube.com/watch? $v=d T c B V h 42 v j g$. Página visitada el 26 de julio de 2014 .

39 El Tribunal Constitucional se refiere, por ejemplo, al escudo de la Municipalidad de Lima, que contiene una estrella y tres coronas alusivas a la estrella de Belén y los Reyes Magos, o al escudo de la Universidad Nacional Mayor de San Marcos, que contiene la imagen del santo escribiendo un evangelio (fundamento 42). 
las clases trabajadoras, o sus condiciones de remuneración, o lo elementos económicos principalmente concernientes a la productividad en este sector.... ${ }^{40}$.

En ese mismo caso, el voto del magistrado MENDOZA MARTELO — contrario al de la mayoría - consideró que debía tomarse en cuenta el carácter pluralista del Estado colombiano y que, en su opinión supone ser tolerante con las tradiciones culturales «que si bien tienen un contenido religioso, no se agotan o limitan en éste, razón por la cual no constituyen fuente de vulneración del principio de neutralidad estatal que rige las relaciones iglesia-estado dentro de un Estado laico».

El argumento del pluralismo ha sido usualmente utilizado para avalar este tipo de promociones estatales vinculadas a expresiones religiosas y también culturales. No obstante, consideramos que eso no debe cegar el hecho de que la laicidad bien entendida impide respaldar concepciones o manifestaciones religiosas (o antirreligiosas) particulares. El hecho de que muchas de ellas contengan a su vez un matiz cultural no las deja de hacer religiosas y por ello no deberían pasar de contrabando a partir de la aludida referencia al pluralismo. Por eso, creemos que es fundamental — con lo difícil que puede ser determinarlo en algunos casos- tomar en cuenta el test de predominancia que propone la Corte colombiana. De lo contrario, el principio de laicidad sería prácticamente letra muerta en relación con la presencia de muchos símbolos religioso (en especial de los que, por tradición histórica, tienen predominancia en cada contexto: en nuestro caso los católicos).

Como dice Ruiz Miguel (quien, de forma similar, considera que en estos casos debería atenderse a la existencia de una «dominante significación religiosa»), a propósito de lo que fue la cuestionable decisión final adoptada por el Tribunal Europeo de Derechos Humanos en el caso Lautsi y otros c. Italia (2011): «Hay casos, como precisamente el del crucifijo en las escuelas, en los que la opción pluralista no es posible» (Ruiz Miguel, 2013: 22). Y no lo es, justamente, porque el Estado tendría que verse obligado a determinar los criterios de aceptabilidad de ciertas manifestaciones y, de ese modo, comprometerse con una valoración positiva o negativa de los mismos, con lo cual dejaría de lado su neutralidad sobre las diversas concepciones del bien o de lo bueno, que es propia de la tradición liberal. Como se dijo, la neutralidad, propia de la laicidad liberal, supone no sólo no distinguir en el valor de ciertas religiones, sino respecto del valor de lo religioso en sí. Por eso, dice el autor que la laicidad positiva tornada en cierta forma de ecumenismo (o trato preferente a toda opción religiosa, con exclusión de las no religiosas) supone un cierto tipo de confesionalismo (RUIZ MigUEL, 2013: 45).

Por lo dicho hasta aquí, creemos que en la cuestión de la relación que puede presentarse entre símbolos religiosos y tradiciones culturales lo importante es atender al nivel de incidencia que tiene el mensaje religioso en el caso concreto, y eso supone una valoración que no puede ser sino particular y contextual. Por eso, nuestro Tribunal Constitucional incurre en una mala argumentación cuando al valorar la posible prohibición de ciertas manifestaciones de fe compara casos que no son comparables entre sí. En el fundamento 50 de la sentencia referida al caso del crucifijo en las salas y despachos judiciales señala:

40 Sentencia C-766/10, de 22 de septiembre de 2010, 33-35. 
Plantearse obligar al Estado al retiro de un símbolo religioso que ya existe y cuya presencia se explica por la tradición del país, implica preguntarse si la mera presencia del crucifijo o la Biblia tienen la capacidad de perturbar a un no creyente al punto de afectar su libertad religiosa. Si el impacto de la sola presencia silenciosa de un objeto en un espacio público representase un trastorno de tal entidad, habría igualmente que prohibir la exposición de símbolos religiosos en las calles, como las cruces en la cima de los templos, ya que su presencia podría resultar emocionalmente perturbadora para los no creyentes.

Así, por ejemplo, el Estado, en nombre de una supuesta laicidad, tendría la obligación de retirar la cruz del cerro San Cristóbal o prohibir el recorrido por lugares públicos de la procesión del Señor de los Milagros, o suprimir del calendario de feriados no laborables fechas de origen religioso católico como la Navidad o el Jueves o el Viernes Santo, con el argumento de que de lo contrario se ofende a los miembros de religiones no católicas, agnósticos o ateos, que pueden verse emocionalmente afectados por la sola presencia de símbolos religiosos católicos en lugares públicos o porque dichos feriados están marcados por una celebración o, en su caso, conmemoración ligada a la religión católica.

Si el Estado procediera así, estaría «protegiendo» en realidad «emociones» de orden meramente subjetivo, antes que derechos fundamentales como la libertad religiosa.

En primer lugar, la argumentación del Tribunal no se centra en el aspecto principal de la discusión, pues hace recaer la misma en la posible afectación emocional del demandante (aunque, es verdad que ese fue el argumento sostenido por él). El problema con la presencia de los símbolos en cuestión en un Estado constitucional no es si estos afectan la sensibilidad de algunos (de hecho, el derecho no está para proteger sensibilidades), sino si con eso se afecta la neutralidad de Estado y en último término el principio de igualdad.

Luego, como dijimos, alude a casos que no son comparables entre sí, yendo de forma efectista y falaz contra uno de los criterios centrales de la ponderación. No es lo mismo retirar crucifijos de las salas judiciales (signo claro de una fe, y no mero elemento cultural, situado además en un espacio público institucional) que retirar esa misma cruz del cerro San Cristóbal (un espacio público, pero no institucional). Tampoco sería lo mismo prohibir el recorrido por lugares públicos de la procesión del Señor de los Milagros (hecho que no debería prohibirse) que promover o aceptar su recorrido dentro de establecimientos públicos institucionales (como juzgados, ministerios, etc.).

Esa falta de matices se advierte también en el caso en que el Tribunal consideró infundada una demanda de amparo, presentada por un ciudadano evangélico, para que se ordene al Congreso se abstenga de aprobar un Proyecto de Ley que buscaba declarar al Señor de los Milagros como Patrono del Perú (luego «Señor de los Milagros Patrono de la Espiritualidad Religiosa Católica del Perú» y «símbolo de religiosidad y sentimiento popular»). En los considerandos del caso, el Tribunal sostiene que:

Así se explica que diversos signos de identidad del Estado, como escudos o nombres de municipios o instituciones públicas, así como conmemoraciones o actuaciones institucionales (por ejemplo, la tradicional Misa y Te Deum por el aniversario de la independencia nacional) se encuentren vinculados a la religión católica o resulte reconocible su origen religioso cristiano, como lo que acontece también con nuestro himno nacional $[\ll[\ldots]$ antes niegue sus luces el sol, que faltemos al voto solemne que la patria al Eterno elevó» (coro); $\ll[\ldots]$ renovemos el gran juramento que rendimos al Dios de Jacob» (estrofa VI) $]^{41}$.

\footnotetext{
${ }^{41}$ Fundamento 17 de la sentencia recaída en el expediente núm. 03372-2011-PA/TC.
} 
En relación con la denominada Misa y Te Deum, a la que se refiere el Tribunal, nos parece que es el mejor ejemplo de lo que no constituye laicidad del Estado. Si una misa no tiene contenido predominantemente religioso no vemos qué otra cosa podría tenerlo. Una misa no es una cuestión cultural (o meramente cultural, pues obviamente casi cualquier rito religioso es cultural también), es una manifestación propia de una fe. Por tanto, es engañoso sostener que la La Misa y Te Deum es un signo identitario de la nación, sin atender a que se trata de una tradición claramente religiosa, con rito y sermón incluido, y al que asisten las principales autoridades del Estado, no en su calidad de fieles sino de representantes de un Estado que se supone laico.

Al contrario, el himno nacional es obviamente un símbolo patrio y sus estrofas alusivas a Dios pueden entenderse en función al momento histórico en que fue creado. Aunque a algunos no creyentes pueda resultarles chocante la referencia a Dios, sería un despropósito — no pensamos que sea razonable - proponer una iniciativa a fin de eliminar esas menciones que surgieron en un momento claramente determinado por la religiosidad y la falta de distinción entre los ámbitos religioso y estatal. No se trata, por tanto, de ir quitando estrofas al himno ni de eliminar los nombres santos de las calles y plazas que así los obtuvieron históricamente. La ponderación en cada caso permitirá mostrar cuándo nos encontramos ante una situación predominantemente religiosa y cuándo ésta ha ido perdiendo esa centralidad. Pero que se diga que el crucifijo o, peor, una misa no tienen contenido esencialmente religioso es un despropósito.

Ahora bien, en cuanto al uso del argumento de la identidad nacional que, de algún modo, pretende conducirnos de la sacralidad religiosa — claramente inadmisible en el Estado constitucional y democrático — a cierto tipo de sacralidad laica — la de los símbolos patrios- es curioso advertir cómo el argumento cultural intenta pasar de una versión meramente comunitarista a una, usualmente más aceptada, forma de republicanismo. Así, los símbolos religiosos se asocian o ligan a símbolos nacionales que, a diferencia de los religiosos, sí sería bienvenidos en el ámbito público. Este argumento, sin embargo, suele incurrir en nuevas falacias y trampas. En Lautsi, por ejemplo, se cita al crucifijo como un símbolo cultural cuyo valor derivaría de su vinculación con el desarrollo de la civilización europea. Así, se ata cristianismo y cultura europea y se introduce una valoración positiva, avalada y promovida por el Estado, de lo que no deja de ser un símbolo religioso. Ese mismo razonamiento es usado por nuestro Tribunal Constitucional cuando dice que «no puede soslayarse que la religión católica ha sido y es la fe tradicional del pueblo peruano - la cual por varias razones se articula a nuestro concepto mismo de nación— ${ }^{42}$.

Como explica Rainer FORST, el hecho de identificar las creencias de una mayoría con las bases de las instituciones políticas viola el principio de justificación de la justicia (en una democracia las instituciones se deben justificar a partir de razones recíprocamente aceptadas, no de razones particulares, como las derivadas de una fe determinada) y de igual respeto (derivado del principio anterior, pues nos exige respetar el derecho a la justificación que tienen los otros a través de razones que puedan ser recíprocamente aceptables; lo que excluye, una vez más, las razones privadas de una fe) (FORST, 2004: 317-318).

42 Fundamento 18 de la sentencia recaída en el expediente núm. 03372-2011-PA/TC. 
Asimismo, FORST nos recuerda que si se aceptara la idea de que el Estado liberal se construye sobre una base ética común, entonces la dialéctica de la tolerancia (vinculada a los principios de justificación e igual respeto) podría peligrar. Como bien dice el autor, habría un problema con el Estado liberal y democrático si éste necesitara volver sobre sus supuestas bases culturales o éticas, vinculadas a los valores o creencias de alguna religión particular, para poder subsistir (FORST, 2004: 320).

\section{CONCLUSIONES}

El denominado retorno del fenómeno religioso ha significado una revisión del discurso de la modernidad en torno a la secularización y, con ello, al espacio que tendría la religión en el ámbito público.

En ese contexto, conceptos como los de laicidad y neutralidad estatal frente a lo religioso son puestos en entredicho y se discute también cual es el lugar que debería corresponderle a la religión (y al discurso religioso) en el marco de los actuales Estados constitucionales y de las sociedades postseculares, en términos de HABERMAS.

La laicidad del Estado supone que éste no deba establecer una valoración favorable ni desfavorable de ciertas creencias, o incluso del propio hecho de creer en Dios (aspectos que en todo caso le toca valorar a la propia religión, a la filosofía, a la psicología o alguna otra dimensión del saber humano). Este requisito de neutralidad en un Estado constitucional y democrático, no se justifica en una cerrada concepción racionalista o cientificista, sino en la idea — propia del pensamiento liberal— de que es conveniente que el Estado se mantenga al margen de la valoración de las particulares concepciones del bien (incluidas la religiosa) y así evite una intromisión de tipo perfeccionista en la autonomía del individuo o trate de forma discriminatoria a algunos individuos o grupos.

Leída en clave de libertad positiva, en cambio, la libertad religiosa es entendida por algunos como una invitación a la promoción - y valoración positiva - de lo religioso por parte del Estado. Esta situación supone la adopción de un modelo de laicidad cuestionable, en la medida que no sólo afecta al principio de neutralidad que debe mantener el Estado frente a las confesiones religiosas y frente al hecho mismo de lo religioso, sino que puede terminar vulnerando los derechos de libertad y de igualdad que dicho principio, precisamente, pretende garantizar en un Estado democrático.

De este modo, se ofrece un tratamiento diferenciado a los creyentes y no creyentes, condicionado por el mayor o menor grado de institucionalidad de su creencia. Ello supone una concepción comunitarista que apunta a la mayor protección de los derechos del grupo que del individuos (o que, en todo caso, protege los derechos del individuo en la medida que forme parte de un grupo, en este caso religioso).

Pero además, esta visión de tipo comunitarista ni siquiera se sostiene en el argumento, usualmente defendido por el comunitarismo, y que en ocasiones puede resultar atendible, referido a la necesidad de adoptar políticas de reconocimiento que permitan reparar situaciones de injusticia cometidas contra ciertos grupos tradicionalmente excluidos. En el caso de las medidas de colaboración con la Iglesia católica, por ejemplo, 
se presentan respecto de una creencia mayoritaria y asentada, que tiene una posición dominante en la sociedad.

En el caso peruano, aunque desde un punto de vista formal el Estado se define como laico, tanto la interpretación de las normas que regulan este tema como la actuación de los actores públicos y privados involucrados muestran una concepción de laicidad y de neutralidad del Estado muy deficitaria.

\section{BIBLIOGRAFÍA}

ABAD, S., 2012: ¿Es el Perú un Estado laico? Análisis Jurídico desde los derechos sexuales y derechos reproductivos, Lima; Católicas por el Derecho a Decidir - Perú.

Bauman, Z., 2006: Vida líquida, Barcelona: Paidós.

BECK, U., 2009: El Dios personal. La individualización de la religión y el «espíritu» del cosmopolitismo, Barcelona: Paidós.

Berger, P., 2008: «Secularization falsified», First Things, en bttp://www.firstthings.com/ article/2008/01/002-secularization-falsified-1. Consulta: 12 de julio de 2013.

BERLIN, I., 2005: Dos conceptos de libertad y otros escritos, Madrid: Alianza.

Bohoslavsky, E., 2013: «Laicidad y América Latina», Colección de Cuadernos Jorge Carpizo. Para entender y pensar la laicidad, núm. 11, Instituto de Investigaciones Jurídicas UNAM.

BlanCARTE, R., 2008: «Laicidad y Laicismo en América Latina», Estudios Sociológicos, núm. 1 (vol. XXVI).

— 2011: «América Latina: Entre pluri-confesionalidad y laicidad», Civitas, núm. 2 (vol. 11).

CAlHoun, C., 2011: «Epílogo», en HaBermas, TAYLOR et al., El poder de la religión en la esfera pública, Madrid: Trotta.

CARABANTE, J., 2012: «De laicista a laico. Jürgen Habermas y el uso estratégico de las creencias religiosas», Cuadernos de pensamiento político, abril-junio.

Chiassoni, P., 2013: «Laicidad y libertad religiosa», Colección de Cuadernos Jorge Carpizo. Para entender y pensar la laicidad, núm. 10, Instituto de Investigaciones Jurídicas UNAM.

EAgLeton, T., 2012: Razón, fe y revolución, Barcelona: Paidós.

FERRARA, A., 2007: «The West Blinded by the Ideology of Secularization», Reset DOC, en bttp:// www.resetdoc.org/story/00000000298. Consulta: el 16 de julio de 2013.

Flores D’ARCAIS, P., 2008: «Once tesis contra Habermas», Claves de Razón Práctica, 179: 56-60.

FRASER, N., 2008: Escalas de justicia, Barcelona: Herder.

FORST, R., 2004: «The limits of toleration», Constellations, 11 (3): 312-325.

GARCíA FigueroA, A., 2007: «La nueva asignatura de Educación para la Ciudadanía y los derechos humanos. Un test para la racionalidad del sistema educativo», Sistema, 199: 61-78.

HABERMAS, J., 2006: «La religión en la esfera pública. Los presupuestos cognitivos para el «uso público de la razón» de los ciudadanos religiosos y seculares», Entre naturalismo y religión, Barcelona: Paidós.

— 2008: «La voz pública de la religión. Respuesta a la tesis de Paolo Flores d'Arcais», Claves de Razón Práctica, 180: 4-6.

- 2011: «Lo político: el sentido racional de una cuestionable herencia de la teología política», en HABERMAS, TAYLOR et al., El poder de la religión en la esfera pública, Madrid: Trotta.

Huaco, M., 2013: Procesos constituyentes y discursos contrahegemónicos sobre laicidad, sexualidad y religión, Buenos Aires: CLACSO. 
JudT, T., 2011: Algo va mal, Madrid: Taurus Pensamiento, 5. ${ }^{\text {a ed. }}$

MACluRE, J., y TAYLOR, C., 2011: Laicidad y libertad de conciencia, Madrid: Alianza Editorial.

Navarro-Valls, R., y Ruiz Miguel, A., 2009: Laicismo y Constitución, Madrid: Fundación Coloquio Jurídico Europeo, 2. ${ }^{\mathrm{a}}$ ed.

Nussbaum, M., 2011: Libertad de conciencia: el ataque a la igualdad de respeto, Buenos Aires: Katz.

- 2013: La nueva intolerancia religiosa. Cómo superar el miedo en una época de inseguridad, Barcelona: Paidós.

OFFE, C., 1998: «Homogeneity and constitutional democracy: coping with identity conflicts through group rights», The journal of political philosophy, 2 (6): 113-141.

Ollero, A., 2007: «Laicidad y laicismo en el marco de la Constitución española», Anuario de Filosofía del Derecho, 24: 265-276.

— 2009: «Igualdad, laicidad y religiones», Anuario de la Facultad de Derecho de la Universidad Autónoma de Madrid, 13: 205-216.

PRIETO, L., 2013: El constitucionalismo de los derechos. Ensayos de filosofía jurídica, Madrid: Trotta.

Quesada Castro, F., 2005: «Democracia y virtudes públicas», en Cerezo (ed.), Democracia y virtudes cívicas, Madrid: Biblioteca Nueva.

Rawls, J., 1995: Liberalismo político, México: Fondo de Cultura Económica, 3. a ed.

- 2001: El derecho de gentes y Una revisión de la idea de razón pública, Barcelona: Paidós.

- 2002: La justicia como equidad. Una reformulación, Barcelona: Paidós.

ReviLLA, M., 2013: «El sistema de relación Iglesia-Estado peruano: Los principios constitucionales del derecho eclesiástico del Estado en el ordenamiento jurídico peruano», Pensamiento Constitucional, 18: 447-468.

REY, F., 2005: « La laicidad “A la francesa”: ¿Modelo o excepción?», Persona y Derecho, 53: 37-64.

— 2011: «Símbolos religiosos en espacios públicos (del Tribunal Europeo de Derechos Humanos al Tribunal Constitucional peruano», Memoria del X Congreso de Derecho Constitucional del Perú.

Ruiz Miguel, A., 2010: «La laicidad y el eterno retorno de la religión», en VASQUEZ, RUIZ y VILajosana (eds.), Democracia, religión y Constitución, Madrid: Fundación Coloquio Jurídico Europeo.

- 2013: «Laicidad y Constitución», Colección de Cuadernos Jorge Carpizo. Para entender y pensar la laicidad, núm. 8, Instituto de Investigaciones Jurídicas UNAM.

Ruiz Miguel, A., y Navarro-Valls, R., 2009: Laicismo y Constitución, Madrid: Fundación Coloquio Jurídico Europeo.

SEN, A., 2007: Identidad y violencia: la ilusión del destino, Madrid: Katz.

Todorov, T., 2008: El miedo a los bárbaros. Más allá del choque de civilizaciones, Barcelona: Galaxia Gutenberg/Círculo de lectores.

VAGgIONE, J., 2008: Religión y sexualidad: Entre el absolutismo y la diversidad, Córdoba: Católicas por el Derecho a Decidir. 